\title{
EQUOTERAPIA E APRENDIZAGEM DA CRIANÇA COM TRANSTORNO DE DÉFICIT DE ATENÇÃO E HIPERETIVIDADE: UM ESTUDO DE CASO
}

\author{
Percília De Oliveira Rodrigues ${ }^{1}$, Jaqueline Batista de Oliveira Costa ${ }^{2}$ \\ ${ }^{1}$ Discente do Curso de Pedagogia da Universidade do Oeste Paulista - UNOESTE - Presidente Prudente. ${ }^{2}$ Docente do \\ Curso de Psicologia da Faculdade de Ciências Humana - Universidade Federal da Grande Dourados/UFGD - Dourados - \\ MS. Email: perrodrigues@hotmail.com
}

\section{RESUMO}

A presente pesquisa teve como objetivo conhecer as contribuições da equoterapia para o ensino e a aprendizagem de crianças diagnosticadas com Transtorno de Déficit de Atenção e Hiperatividade (TDA/H). Especificamente buscamos destacar algumas estratégias e atividades pedagógicas que, quando associadas à equoterapia, pode favorecer o desenvolvimento de crianças com TDA/H. Esta é uma pesquisa qualitativa, do tipo estudo de caso, que foi realizada junto a uma criança de 05 anos atendida pelo projeto de extensão denominado "Equitação no Auxílio ao Trabalho Pedagógico". Para a coleta dos dados foram realizadas intervenções com atividades pedagógicas e observações do comportamento da criança durante as seções de equoterapia. Os dados coletados foram submetidos a um procedimento de análise qualitativo. Esta pesquisa evidenciou que a equoterapia contribuiu muito no desenvolvimento da aprendizagem do praticante estudado, especialmente favorecendo o estabelecimento de laço afetivos e no aperfeiçoamento da socialização com outras pessoas.

Palavras-chave: Equoterapia. Transtorno de Déficit de Atenção e Hiperatividade. Aprendizagem.

\section{INTRODUÇÃO}

A equoterapia, nos últimos anos, tem se destacado como recurso terapêutico comumente aplicado nas áreas da saúde e educação. Na saúde pode ser utilizada com pacientes que apresentam comprometimento físico, sensorial e/ou mental e na educação pode ser utilizada com indivíduos com necessidades educacionais especiais (SILVA, GRUBITS, 2004).

O termo equoterapia é utilizado para designar todas as práticas que usam o cavalo, técnicas de equitação e atividades equestres, visando o desenvolvimento global, a reabilitação e/ou educação de pessoas com necessidades físicas e educacionais especiais. Trata-se, portanto, de um recurso terapêutico, ou melhor, de um conjunto de técnicas reeducativas que atuam para superar danos sensoriais, cognitivos e comportamentais, e que desenvolvem atividades lúdicoesportivas utilizando o cavalo (ANDE, 2007).

Uma vez que a equoterapia favorece o desenvolvimento da capacidade de manter a atenção e concentração, estabelecer vínculos afetivos e a autoconfiança dos indivíduos que a praticam, ela assume um caráter de suma importância, se aliada ao processo pedagógico de crianças e adolescentes com distúrbios de aprendizagem diversos (ANDE, 2007). 
No Brasil, o atendimento às pessoas com Necessidades Educacionais Especiais em equoterapia é uma das atividades que vem se desenvolvendo há vários anos. Contudo, ainda existem poucos estudos que associam a utilização da equoterapia ao processo de ensino e aprendizagem de crianças com TDA/H. A escassez de estudos sobre o tema justifica a relevância desse estudo.

O Transtorno do Déficit de Atenção e Hiperatividade (TDA/H) é um distúrbio que afeta a aprendizagem de milhares de crianças no Brasil e no mundo. Tem sido apontado como um distúrbio neurológico, que envolve o córtex pré-frontal. Trata-se do distúrbio do neurodesenvolvimento, mais comum na infância, e está incluído entre as doenças crônicas mais prevalentes entre escolares. Estima-se que 3\% a 6\% das crianças em idade escolar apresentam TDA/H (CAPELLINI et al, 2007). Segundo estudiosos e pesquisadores, o TDA/H é constituído de três agravantes primários: a dificuldade na atenção, controle e inibição dos impulsos e da atividade excessiva. (BELLI, 2008).

Belli (2008) afirma que tendo em vista os critérios e sintomas é possível identificar três tipos de TDAH: O Tipo Combinado: Quando a pessoa se enquadra em seis ou mais itens das duas listas de sintomas. Geralmente esse indivíduo terá dificuldades em se concentrar e são muito ativas (TDA com Hiperatividade). O Tipo Predominante Desatento: É quando a pessoa se enquadra em seis dos nove itens de desatenção somente. Portanto sua maior dificuldade é de se concentrar, manter-se atento, organizar e terminar suas atividades (TDA sem Hiperatividade). O Tipo Predominante Hiperativo Impulsivo: Esta versão é utilizada em crianças de 4 a 5 anos onde é mais difícil constatar o diagnóstico de desatenção.

Dados da literatura assinalam para uma forte incidência da dificuldade de aprendizagem em crianças com TDA/H, na ordem de $20 \%$ a $30 \%$ dos casos. Dentre as dificuldades de aprendizagem, os transtornos de leitura e escrita são, frequentemente, os mais presentes (SILVA, 2006). Isso ocorre por apresentarem limitações no fluxo de fala espontânea, desorganização na elaboração de formas gramaticais, dificuldades de memória e compreensão auditiva, além de trocas ortográficas (ZORZI, 1993).

Tanto o TDA/H como os demais distúrbios da aprendizagem são condições genéticoneurológicas que, se não forem diagnosticadas e devidamente tratadas, podem acarretar o fracasso escolar dos indivíduos e persistir até a adolescência ou vida adulta. Nessa perspectiva, faz-se necessário um diagnóstico precoce e um atendimento educacional especializado à criança que apresente o transtorno. 
Após o diagnóstico, é possível estabelecer métodos de ensino eficazes. Segundo Santos (2000), esta inovadora terapia complementa o tratamento tradicional, proporcionando o desenvolvimento das crianças. A satisfação de estar em cima de um animal tão imponente, faz com que o praticante tenha a sensação de bem estar. "Esta alegria transforma a seriedade da terapia numa sessão em que o aspecto lúdico predomina" (SANTOS, 2000, p. 60).

Para Moreira (2010), por se tratar de um ambiente fora do comum, a equoterapia se torna menos cansativa para o paciente, tendo maior aceitação e melhor desempenho do mesmo. Na equoterapia o cavalo é o grande motivador terapêutico que transmite ao praticante suas ações através de movimentos, exigindo do praticante equilíbrio, concentração, atenção e postura. Apesar de ser um animal de grande porte, o cavalo é muito dócil, o que contribui na hora do adestramento para utilizá-lo neste tipo de prática terapêutica. O cavalo transmite aos praticantes durante as sessões de equoterapia, uma estimulação de movimentos oscilatórios tridimensionais, proporcionando avanços no desenvolvimento das dificuldades tidas pelo praticante. Desse modo, a equoterapia tem proporcionado benefícios e contribuído muito na vida desses praticantes com comprometimento físico, motor, cognitivo, social, psicológico e comportamental (MOREIRA, 2010).

Nesse sentido, o objetivo geral desse estudo consistiu em conhecer as contribuições da equoterapia para o ensino e a aprendizagem de uma criança com TDA/H. Especificamente pretende-se Identificar estratégias/atividades pedagógicas que, quando associadas à equoterapia, podem favorecer a aprendizagem e o desenvolvimento de crianças com TDA/H.

\section{METODOLOGIA}

O presente estudo caracterizou-se como uma pesquisa qualitativa do tipo estudo de caso. Foi desenvolvido junto a uma criança ${ }^{1}$ de cinco anos, com diagnóstico clínico (neurologista e psicóloga) de TDA/H, atendida pelo projeto de extensão denominado "Equitação no Auxílio ao Trabalho Pedagógico". Após aprovação do estudo pelo Comitê de Ética e Pesquisa (protocolo 940) da Universidade do Oeste Paulista - UNOESTE- deu-se início ao estudo. A princípio foi feito uma aproximação da criança com a pesquisadora e o reconhecimento do ambiente físico onde iríamos

\footnotetext{
${ }^{1}$ O projeto de extensão denominado “Equitação no Auxílio ao Trabalho Pedagógico" foi implantado em março de 2011. Atualmente temos apenas uma criança com TDA/H sendo atendida por esse projeto extensivo. Existe a possibilidade de ampliarmos o atendimento a outras crianças, com distúrbio dessa natureza, inclusive a alunos de escolas públicas de Presidente Prudente. No entanto, o Centro de Reabilitação Equestre da UNOESTE não dispõe, no momento, de estrutura física para esse empreendimento. Dessa forma, o presente estudo de caso foi realizado apenas com um sujeito.
} 
trabalhar, para posteriormente desenvolvermos atividades pertinentes que auxiliassem no desenvolvimento cognitivo da criança.

A criança com TDA/H apresenta sérios comprometimento na capacidade de atenção e controle da impulsividade. Desse modo, procuramos desenvolver brincadeiras e jogos lúdicos que incidissem sobre esses aspectos. As atividades foram curtas e diversificadas, para que a criança conseguisse concluí-las sem se dispersar. Foram utilizados jogos de desafios como: (Adivinha que animal é?, Qual é a cor?, Dominó e quebra cabeça); atividades com figuras (para associação número ou letra à figura); atividades de leitura de historias infantis; atividades de memorização e desafio para que a criança recontasse ou desenhasse as histórias ouvidas. Para realização de todas estas atividades foram utilizados materiais pedagógicos diversificados, tais como: alfabeto móvel, avental pedagógico utilizado para contar história, fantoches de personagens de contos infantis; revistas e livros de literatura infantil, sucatas, etc.

\section{RESULTADOS}

No mês de abril foram realizadas duas sessões de observação, nas quais foram desenvolvidas atividades de aproximação e socialização do praticante com o cavalo e com a equipe multidisciplinar. Foi feito, ainda, um levantamento das atividades que o praticante demonstrava maior interesse e compreensão.

No primeiro encontro, o praticante mostrou-se muito agressivo e apresentava dificuldades na interação social, no diálogo, e quase não sorria. Fomos, aos poucos, nos aproximando e mediando a interação do praticante com o cavalo, pois percebemos que a construção de confiança e afeto do praticante conosco seria algo que poderia levar semanas ou até mesmo meses. Conversamos muito com ele no momento em que estava sobre o cavalo, abordamos alguns assuntos como: O que você gota de fazer? Gosta de contar ou ouvir histórias? Gosta da história de Chapeuzinho vermelho, João e Maria, Os três porquinhos, João e o Pé de Feijão? Você gosta de música? Sabe alguma música? Gosta de ir á escola? Prefere desenhos ou filmes? Sem demonstrar muito interesse pelo assunto o praticante respondia somente sim ou não de cabeça erguida e com um olhar muito distante. Assim foi encerrada a primeira sessão de equoterapia, sem muito entusiasmo e interação do praticante conosco.

No segundo encontro preparamos algumas atividades pedagógicas para avaliarmos os conhecimentos prévios do praticante e a sua capacidade de memorização. Iniciamos com numerais de 1 a 5 . Nesta atividade o praticante deveria ver o número e associar o símbolo 
numérico à quantidade de elementos que ele representa e nos dar a respectiva resposta. Nesta atividade o praticante interagiu e demonstrou boa capacidade de memorização e entendimento, porém, o cansaço e o desinteresse pelas atividades veio com muita facilidade. Não obtivemos muito êxito nesse primeiro mês.

No mês de maio foi trabalhadas três sessões de equoterapia, pois o praticante mostrava-se excessivamente sonolento, e por vezes cochilava sobre o cavalo. Nas sessões seguintes, conseguimos avançar um pouco mais. Preparamos uma atividade pedagógica, utilizando o conto da história de João e Maria. Relacionamos as pedras que João jogava pela floresta, para demarcar caminho, com os numerais, assim a cada quantidade de pedra que João jogava pelo caminho, nós mostrávamos o número móvel para saber se o praticante estava se concentrando na atividade e se conseguia distinguir aquele determinado número mostrado. $\mathrm{O}$ praticante interagiu bem durante a atividade desenvolvida, participando ativamente da história, teve um pouco de timidez no começo, mas, verbalizou os numerais. Manteve a atenção durante toda a atividade trabalhada.

Devido ao sucesso, na sessão seguinte, iniciamos nossa atividade com um novo conto, desta vez, a de Chapeuzinho vermelho. Após a história realizamos a mesma atividade da sessão anterior com os numerais. De modo semelhante foi realizado esse procedimento com as vogais moveis e por fim pedimos ao praticante que verbalizasse palavras que começassem com a letra das vogais que se encontrava em suas mãos. O praticante demonstrou atenção e possuir certo conhecimento dos números e das letras.

Na última sessão do mês de maio reforçamos a atividade com as vogais, porém, nessa ocasião, tivemos uma surpresa o praticante revelou bastante dificuldade em reconhecer as letras, demonstrou confusão em diferenciar as vogais: $A, E, I, O, U$.

Assim, resolvemos criar uma associação de vogais com as palavras que iniciavam com elas. Fizemos isso de forma cantada, por exemplo: A de abelha, E de elefante, I de igreja, O de ovo, $U$ de uva, o praticante logo estava reproduzindo com o mesmo ritmo que apresentamos a ele, foi muito satisfatório vê-lo terminar a sua sessão cantarolando.

Após um período de recesso de, praticamente, um mês e meio, retomamos nossas atividades com o praticante em agosto. Porém, no primeiro encontro, percebemos que o praticante estava agitado e demonstrou grande dificuldade em interagir conosco nas atividades. Provavelmente o período prolongado de férias, no qual o praticante ficou sem realizar as sessões de equoterapia, possa ter ocasionado alguns prejuízos na aprendizagem. 
$\mathrm{Na}$ sessão posterior iniciamos com a apresentação das vogais. O praticante reconheceu e verbalizou todas as letras com muita facilidade. Lembrou-se da música que associamos as letras à palavra e cantou do início ao fim das vogais. A de abelha, E de elefante, I de igreja, O de ovo, $\mathrm{U}$ de uva.

Realizamos a contagem dos números apresentando ao praticante cada número e pedíamos que ele nos dissesse a sequencia dos numerais até o algarismo 10. Ele nos pediu então que constássemos a história de Chapeuzinho Vermelho. Nesta ocasião o praticante vibrou sobre o cavalo com os acontecimentos narrados na história. No mês de agosto realizamos duas sessões de observação nas quais percebemos que o praticante revelou haver regredido na aprendizagem dos conteúdos trabalhados por meio das atividades realizadas.

A sessão seguinte foi preparada para executar o jogo da memória. Nesta atividade preparamos peças que possuíam no lado direito números de 1 a 5 e, no lado esquerdo, o desenho de uma fruta. Nessa atividade o praticante tinha que nos dizer em qual número se encontrava a uva, a laranja e assim sucessivamente. Realizamos esta atividade lúdica com o intuito de observar a capacidade de atenção, concentração, memorização e reconhecimento dos números, das imagens e da primeira letra da palavra que inicia o nome da fruta. O praticante demonstrou no início certa resistência à atividade e falta de atenção, mas aos poucos foi interagindo. Ele nos pediu para contar uma nova história e desta vez contamos a dos Três porquinhos, que por sinal ele demonstrou grande motivação pela história.

A atividade pedagógica proposta na sessão seguinte foi a de associação das letras do alfabeto, com palavras que se iniciava com a mesma letra mostrada ao praticante. Nesta atividade ele necessitava conhecer as letras do alfabeto para que conseguisse verbalizar palavras que começavam com a mesma letra. Foi uma forma de fazer o praticante buscar na memória palavras que já faziam parte do seu repertório e contexto e de desenvolver sua atenção e concentração.

No mês seguinte realizamos quatro sessões de observação e nestas reforçamos algumas atividades que auxiliou muito no desenvolvimento cognitivo do praticante. Houve bastante êxito!

Os meses de outubro e novembro não foram tão produtivos, pois o praticante demonstrou dificuldades em fazer atividades que já havia realizado em um curto espaço de tempo. Tivemos apenas uma sessão em cada mês, pois o praticante não compareceu as demais. 


\section{DISCUSSÃO DOS RESULTADOS}

As atividades propostas à criança com TDA/H foram elaboradas tendo em consideração seu nível de desenvolvimento cognitivo. Todavia esta demonstrava dificuldades diversas ou falta de atenção. Uma mesma atividade foi trabalhadas em várias de modo que promovesse o desenvolvimento da habilidade necessária.

Contudo, na maioria das vezes, era necessário interromper e reformular a atividade de forma que atraísse a atenção dele. Constatamos que com crianças com TDA/H, o uso de atividades desmotivantes é pouco produtivo para a aprendizagem. É necessário que se busque estratégias diferenciadas, especialmente aquelas de caráter lúdico. Nesse sentido, sugere-se o uso de jogos, brincadeiras e, no caso do sujeito desta pesquisa o uso de histórias infantis foi determinante para prender sua atenção.

É importante ressaltar que todas as atividades foram realizadas sobre o cavalo em movimento. O uso do cavalo, em algumas ocasiões pode parece mero pretexto, entretanto, conforme Moreira (2010) o cavalo torna a atividade menos cansativa para o praticante. Faz com que este tenha maior aceitação, se concentre e a desempenha com maior êxito. Cabe destacar ainda que os movimentos tridimensionais exigem do praticante equilíbrio, concentração, atenção e postura.

A despeito de todas as dificuldades encontradas quanto à falta de recursos, materiais e de recursos humanos percebemos que a Equoterapia, quando associada a diferentes atividades pedagógicas planejadas, contribuiu muito no desenvolvimento da aprendizagem do praticante. Constatamos ainda que favorece o desenvolvimento de habilidades sociais, tais como: aprender a esperar por sua vez na hora de realizar as tarefas; controlar impulsos agressivos e a inquietação. Promove também a interação social entre praticante e equipe multidisciplinar e com o cavalo.

Ao abordar informalmente a mãe do praticante de nosso estudo, e perguntar se em casa ou na escola havia percebido alguma mudança no comportamento e nas ações do praticante, ela nos relatou que sim, principalmente na escola onde a professora relatou significativos avanços na aprendizagem e na socialização com os colegas da sala.

Por motivos que não sabemos quais, no ano de 2012, quando retomamos as sessões de equoterapia, a mãe não nos procurou mais e após diversas tentativas de contato fomos informadas da desistência no tratamento. 


\section{CONCLUSÃO}

A presente pesquisa buscou conhecer as contribuições que a equoterapia pode proporcionar a praticantes com TDA/H, quando associada a atividades de natureza pedagógicas diversas. Confirmado o que a ANDE (2007) assegura, nossa pesquisa evidenciou que a Equoterapia pode ser um alternativa eficaz no desenvolvimento da capacidade de manter a atenção e concentração, estabelecer vínculos afetivos e a autoconfiança dos indivíduos que a praticam. Ao analisarmos os dados coletados durante o estudo, constatamos que realmente, através da equoterapia a criança consegue aumentar não só a sua concentração, mas também a sua capacidade física e motora e até mesmo a sua autoestima, pois, estando sobre o cavalo, o praticante se torna confiante e acredita no seu potencial, podendo realizar coisas antes impossível. Desse modo, acreditamos que a equoterapia assume um caráter de suma importância, se aliada ao processo de aprendizagem de crianças e adolescentes com distúrbios de aprendizagem diversos. (ANDE, 2007). Contudo, compete aos profissionais que utilizam desta ferramenta selecionar, planejar e, se necessário, adaptar atividades pedagógicas que podem ser utilizadas com estas crianças.

O presente estudo aponta para a necessidade de novos estudos que reforcem os dados encontrados nesta pesquisa, a fim de que ampliemos o rol de estratégias eficazes no processo de ensino e aprendizagem de criança com TDA/H.

\section{REFERÊNCIAS}

ANDE BRASIL. Associação Nacional de Equoterapia - ANDE. Apostila do Curso Básico de Equoterapia. Brasília, 2007.

BELLI, A. A. TDAH! E agora? : A dificuldade da escola e da família no cuidado e no relacionamento com crianças e adolescentes portadores de transtorno de déficit de atenção/hiperatividade. 1a. ed. São Paulo: Editora STS, 2008.

CAPELLINI, Simone Aparecida et al. Desempenho de escolares bons leitores, com dislexia e com transtorno do déficit de atenção e hiperatividade em nomeação automática rápida. Ver. Soc. Bras. Fonoaudiologia. 2007;12(2):114-9. http://dx.doi.org/10.1590/S1516-80342007000200008

MOREIRA, L.C.S. O cavalo: um motivador terapêutico. In: SEVERO, J.T. (Org.). Equoterapia: equitação, saúde e educação. 1a. Ed. São Paulo: Editora SENAC São Paulo, 2010. Cap. 4, p. 112119.

SANTOS, F. P. R. dos Equoterapia: uma perspectiva para desenvolvimento da linguagem. Revista Cefac: Atualização Científica em Fonoaudiologia, São Paulo, v. 2, n. 2, Jul./Dez., 2000. Disponível em: 
$<$ http://www.revistacefac.com.br/fasciculo.php?url=1\&form=edicoes/revista/revista22/Artigo\%20 7.pdf>. Acesso em: 27 mar. 2012.

SILVA, Carlos Henrique, GRUBITS, Sonia. Discussão sobre o efeito positivo da equoterapia em crianças cegas. PSIC - Revista de Psicologia da Vetor Editora, Vol. 5, no.2, 2004, pp. 06-13.

SILVA, M. L. Q. S da. Desempenho em Leitura e Escrita de Alunos com Diagnóstico de TDAH. 2006, 168 f. Dissertação (Mestrado em Educação) - Programa de Pós Graduação em Educação, Universidade Federal do Paraná, Curitiba.

ZORZI JL. Aquisição da linguagem infantil: desenvolvimento, alterações, terapia. São Paulo: Pancast;1993.105 p. 